such as Stoneburner and Low-Beer actually maintain that from the start "the government communicated a clear As easy as $A B C$ ? Primary prevention of
sexually transmitted infections T Stammers

Uganda's $A B C$ programme has led to dramatic decreases in HIV infection rates for over a decade. No country in the world has seen its HIV incidence fall through condom promotion alone. Changes in primary sexual behaviour are always present when HIV rates decline. Safer sex is first about partner choice and then condom use, but both are important. There are valid criticisms of the $A B C$ approach but its critics and proponents alike should work together if the Ugandan success is to be maintained and replicated in other countries.

n this issue, Genuis and Genuis draw renewed attention to the success of the ABC strategy (abstinence, being faithful, condom use) in reducing HIV infection rates in Uganda. They suggest that this approach will provide "an adaptable framework for ...STD prevention programmes in other nations" ${ }^{\prime}{ }^{1}$

Although initially, there was much debate about the reality of the Ugandan success, few now dispute the overwhelming evidence showing both the extent and duration of the reduction of HIV infection. ${ }^{2}$ HIV prevalence in Uganda declined from $21.1 \%$ to $9.7 \%$ from 1991 to 1998 across 15 antenatal clinics, with the greatest declines among the younger age groups. In 21 year old army recruits, the decline was from $18.5 \%$ to $4 \%$ (1991-2002) and among blood donors, HIV prevalence fell from $24 \%$ to $7 \%$ (1989-1998). ${ }^{3}$ While there was some geographical variation, HIV prevalence fell in both urban and rural areas and in both men and women.

There also continues to be a decline in the incidence of HIV in Uganda with a $37 \%$ decrease in HIV-1 incidence between the years 1995-99 compared with 199094 in a recently reported study. As incidence is a better measure of the future trends of the disease than prevalence, it seems probable that Ugandan HIV rates will continue to decline at least for the next few years. Little wonder then, that leading researchers of the $\mathrm{ABC}$ methodology claim, "The Ugandan success is equivalent to a vaccine of $80 \%$ effectiveness. Its replication will require changes in global HIV/AIDS intervention policies and their evaluation"'2

CONTROVERSY ON CAUSATION

Althhough the extent of HIV decline in Uganda is incontrovertible, its causes and implications for other countries are still widely contested. For example, there are recurring claims that the HIV reduction in Uganda is mainly attributable to safer sterile injection techniques in clinics. ${ }^{56}$ However, most experts closely involved in assessing the causes of the steep decline in HIV rates in Uganda would agree with Low-Beer's conclusion that the most important single, distinctive factor behind every HIV prevention success is "wide social communication leading to declines in casual sex of up to $65 \%$ at the population level. If this risk avoidance did not occur, HIV did not decline, even with greater resources, condom use, counseling, education and treatment" ${ }^{\prime 7}$

However, there are dissenting voices. David Serwadda, director of the Institute of Public Health at Makerere University in Kampala commented "as a physician who has been involved in Uganda's response to AIDS for twenty years, I fear that one small part of what led to Uganda's success-promoting sexual abstinence-is being overemphasized in policy debates. While abstinence has played an important role in Uganda, it has not been a magic bullet". 8 This contrasts strikingly with Uganda's President, Yoweri Museveni who emphasises that although "condoms have a role to play. Especially in couples who are HIV-positive, they cannot become the main means of stemming the tide of AIDS. . . condoms are not a magic bullet". ${ }^{3}$

The Alan Guttmacher Institute suggests that "informed observers of the Ugandan experience indicate that abstinence-only education was not a significant program intervention during the years when Uganda's HIV prevalence was dropping", ${ }^{9}$ but informed observers warning and prevention recommendation: AIDS or "slim" was fatal and required and immediate population responses based on "zero-grazing," that is, faithfulness to one partner. Condoms were a minor component of the original strategy".2

\section{CONDOM WARS}

A large evidence base shows that consistent, correct condom use offers 90\%95\% protection against HIV infection, although inconsistent use is much less effective at $69 \%{ }^{10}$ The ABC strategy recognises that monogamy puts, for example, the Ugandan wife who is faithful to her HIV infected husband, at high risk of infection and condom use in this situation is of the utmost importance. Genuis and Genuis acknowledge the part that condoms played in controlling the spread of infection in high risk groups such as commercial sex workers in Thailand. Despite this almost universal acceptance of the importance of condoms for high risk partners, unsupported assertions that "since the AIDS virus is smaller than the pores in condoms, they offer no protection against HIV" are still being voiced in some parts of the world. ${ }^{11}$

On the other hand, Amy Coen, president of Population Action International, recently asserted that "the importance of condoms cannot be overstated". ${ }^{12}$ If this were true however, countries with comparable or higher rates of condom use than Uganda, such as Malawi and Kenya should also have lowered their HIV rates. South Africa, for example, which has strongly promoted condom use as the principal means of HIV prevention, remains the world leader in HIV prevalence with a survey in antenatal clinics showing an incidence of $26.5 \%$ in pregnant women in 2002. ${ }^{13}$ There are no examples to date from any country in the world that has reversed a generalised HIV epidemic by means of condom promotion alone.

There may be many reasons for this. Incorrect or inconsistent condom use is not an effective means of prevention of HIV; it has even been argued that this may lead to an increase in transmission. "The possibility that presenting casual sex using a condom as socially acceptable, enjoyable and safe might increase sexual risk behaviour in the general public cannot be dismissed. Condom promotion need not increase sexual activity to produce a negative effect. Even if it attenuates a decrease in the average number of sex partners that would have taken place otherwise in response to HIV/AIDS, it could be 
harmful" ${ }^{14}$ There is concern in the UK that increasing contraception provision without any consideration of the wider effects of this on sexual behaviour, may be counter-productive in its effects on sexual health, and lead to increases in both teen conception and STI rates. ${ }^{15-17}$

While in theory, condom use seems a logical solution to HIV prevention, a comprehensive meta-analysis on the issue concluded "it is disappointing to find so few sexual behaviour interventions that have been evaluated rigorously and shown to be effective in reducing STIs"18 If there are such difficulties with HIV, the problem is even greater for infections such as genital herpes and HPV, where condoms have little or no impact in preventing their rapid spread. Even an article intending to put a positive spin on condom use and highlighting "nonuse" as the "real problem with condoms", none the less contains an illustrative figure showing those having sex with consistent, correct condom use twice a week with an infected partner with either chlamydia, gonorrhea, or syphilis would catch the disease within a two to three year period (rather than a two to three week period without condoms). ${ }^{19}$ Professor Michael Adler acknowledged recently that in the UK, "condom use has gone up, but probably not enough to offset the increase in sexual partners" ${ }^{\prime 20}$

In the developing world, encouraging condom use for "at risk" sex also needs to be realistically viewed within the context of availability. President Museveni quite rightly draws attention to logistic realities in suggesting "In countries like ours, where a mother often has to walk 20 miles to get an aspirin for her sick child ...the question of getting a constant supply of condoms may never be resolved". ${ }^{21}$ Even with unlimited availability however, Hearst and Hulley warn that "even if condoms were $99 \%$ effective, whether one uses condoms would still be less important than the risk status of one's partner". ${ }^{22}$

\section{FRESH EMPHASIS ON FAITHFULNESS}

It is more than 10 years since Hudson ${ }^{23}$ hypothesised that in countries with a widespread heterosexual HIV epidemic, concurrent partnerships were likely to be a major contributing factor. He argued the driving force behind HIV transmission is the initial viraemia when titres of infectious virus are higher than in the asymptomatic phase and when sexual activity is likely to be greater than during the late symptomatic phase up to 10 years later. He recognised that mass condom distribution may not be cost effective compared with the simple message of "have one partner at a time and do not have casual partners when you are in a regular relationship". He concluded that "Health educationalists rather than focusing on the forms of sex that are 'safer' could focus on the types of relationship that are 'safer'. Most Western governments however have found such an emphasis politically unacceptable and have continued to promote the idea that "every one is at equal risk". Safer sex is in fact more about the choice of sexual partner than use of condoms.

The publication in 2004 of three BMJ articles, ${ }^{24-26}$ emphasising partner reduction in preventing the spread of HIV, has raised the profile of the importance of sexual fidelity once again. The Ugandan "zero-grazing" policy of encouraging faithful monogamous relationships resulted in significant changes. The proportion of men with one or more casual partners in the previous year fell from $35 \%$ in 1989 to $15 \%$ in 1995 and for women from $16 \%$ to $6 \%$. Shelton et al concluded that although a direct causal link could not be proved between the "zero-grazing" campaign and the concomitant fall in HIV rates, "it seems likely that it was critical to the success in Uganda". ${ }^{25}$ Partner reduction was reported in every other HIV reduction success story worldwide. ${ }^{25}$

Despite this, the focus on being faithful has met with considerable opposition. Attention is rightly drawn to the fact that marital rape is not a crime in Uganda and many women have difficulty in refusing sex or insisting on condom use for fear that their husbands will beat or sexually abuse them. Women are more than twice as likely as young men in sub-Saharan Africa to be infected with HIV. ${ }^{27}$ The Global Coalition on Women and AIDS has reacted strongly by saying that the $\mathrm{ABC}$ strategy is "wholly inappropriate in many countries where women know little if anything about HIV and are afraid to ask their husband or boyfriend to use a condom"27

These concerns for women's equality are both right and necessary but it is difficult to see how they constitute a valid criticism of $\mathrm{ABC}$ programmes, as similar inequalities in women's rights occur in many other African countries and the benefits of the $A B C$ success have benefited Ugandan women as much as men. The HIV prevalence in pregnant women in Kampala for example, has fallen from $25 \%$ to $14 \% .^{3}$ First lady, Janet Museveni, has spearheaded the $\mathrm{ABC}$ campaign throughout Uganda so that women in particular might be informed about HIV and how to avoid it. Helping women to assert themselves is an intrinsic part of the Ugandan $\mathrm{ABC}$ programme's unrivalled success and is fully compatible with providing women with job training, literacy, and negotiating skills to strengthen their position in the community. ${ }^{28}$

\section{ABSTINENCE - ESSENTIAL BUT NOT ENOUGH}

Although many critics of abstinence resort to ad hominem argument, ${ }^{29}$ rather than peer reviewed evidence, abstinence alone does have problems associated with it. Even among its advocates the term "abstinence" may conjure up Shakespearian images of monks or "nunneries". The use of the terms "saved sex" or deferred sex, may be more useful.

Abstinence focused approaches are obviously not appropriate for teens already sexually active. In Uganda, although the proportion of women aged 15-17 who had ever had sex fell from $50 \%$ in 1988 to $34 \%$ in 2000 , the proportion who had had sex in the previous three months increased between 1988-1995 (when HIV rates were in most rapid decline) among those who were already sexually experienced. ${ }^{30}$ Bellis et al point out that in the UK, there is an "unwillingness to engage with the promiscuous $10 \%$; a significant group...who have multiple sexual partners, (and) may have started sex early in life. For instance one in ten young people have had sex at 14 or younger". ${ }^{31}$ However, they go on to suggest that the abstinent $90 \%$ should be subject to the kind of sex education they consider mandatory for the "promiscuous" $10 \%$, whereas the two constituencies need entirely different approaches.

The government's Independent Advisory Committee on sexual health has no time for abstinence in its latest report. ${ }^{32}$ It erroneously states however, that those who make abstinence pledges are at higher risk of STIs than their nonpledging peers. In fact, the only data on this clearly show that those who made abstinence pledges had lower (but not significantly so) rates of STIs, despite having much lower rates of condom use. $^{33}$ These data do also show that pledging schemes (which are very different from the $\mathrm{ABC}$ approach and are unlikely to be directly transferable outside the USA) do not significantly reduce STI rates six years later. The results also show that in communities with high pledging rates, the overall incidence of STIs is higher among both pledgers and non-pledgers. Ignorance of STIs may well induce complacency and be harmful to pledgers and others in high density pledging settings; any abstinence focused programme should 
include teaching on STIs and their prevention and treatment.

The USA has however had large falls in both teenage conceptions and abortions. With a $30 \%$ decrease in the past decade, teen pregnancies in the USA are now at their lowest level since $1946,{ }^{34}$ and US policy deserves serious consideration. The only peer reviewed published research to date on causation shows that primary behaviour change plays a significant part. Sixty six per cent of the decrease in teenage pregnancies among unmarried girls from 1991 to 19955 is attributed to an increase in abstinence, ${ }^{35}$ and 53\% of the decline in overall teenage pregnancies between 1991 to 2001 is attributed to changes in sexual behaviour including, but not limited to, abstinence. ${ }^{36}$ As yet, the UK government continues to turn a blind eye to such striking evidence.

\section{TIME TO WORK TOGETHER?}

What the ABC success surely teaches is that a range of options is needed to help teenagers to defer sexual intercourse until they are in a secure, committed and loving relationship, to encourage faithfulness and partner reduction among the sexually active, and to promote condom use among those who engage in higher risk sex. The current warfare should end between those who would deny all use of condoms on religious grounds and those who decry abstinence because it cuts across their ideology of a teenager's right to sex.

It is time for change. On World AIDS Day 2004, the Lancet published a commentary entitled "The time has come for common ground on preventing sexual transmission of HIV" ${ }^{\prime 37}$ The same day, Harvard professor, Edward Green, issued a warning that many Western donors were determined to unpick the $\mathrm{ABC}$ strategy, rather than model future policy on it. "We're going to reach a point where infection rates will start going up again and then experts will say $\mathrm{ABC}$ never worked, that there was probably something wrong with data all along". ${ }^{38}$ Both sides of the sexual health debate have vital lessons to learn from Uganda but, if Green is correct, the opportunity to do so may only last for a few more years.

Postgrad Med J 2005;81:273-275.

doi: 10.1136/pgmi.2004.027722

Correspondence to: Dr T Stammers, Department of General Practice, St George's Hospital Medical School, Cranmer Terrace, London SW17, UK; tgstammers@doctors.org uk

\section{REFERENCES}

1 Genuis SJ, Genuis SK. Primary prevention of sexually transmitted disease: applying the $A B C$ strategy. Postgrad Med J 2005:81:299-301.

2 Low-Beer D, Stoneburner RL. Population-level HIV declines and behavioural risk avoidance in Uganda. Science 2004;304:714-18.

3 Low-Beer D, Stoneburner RL. Behaviour and communication change in reducing HIV: is Uganda unique? African Journal of AIDS Research 2003;2:9-21.

4 Mbulaiteye SM, Mahe C, Whitworth JA, et al. Declining HIV-1 incidence and associated prevalence over 10 years in a rural population in SW Uganda: a cohort study. Lancet 2002:360:41-6.

5 Gisselquist D, Rothenberg R, Potterat J, et al Non-sexual transmission of HIV has been overlooked in developing countries. BMJ 2002;324:235.

6 Brody S. Declining HIV rates in Uganda: due to cleaner needles, not abstinence or condoms. Int J STD AIDS 2004;15:440-1.

7 Low-Beer D. Going face to face with AIDS: this is a routinely avoidable disease. Financial Times Nov 8: 2003

8 Boonstra HUS. AIDS policy: priority on treatment, Conservatives' approach to prevention 2003 Guttmacher Report 6 (3). http:// www.guttmacher.org/pubs/tgr/06/3/ gr060301.html (accessed 15 Dec 2004)

9 Dailard C. Understanding 'abstinence': implications for individuals, programs and policies 2003 Guttmacher Report 6 (5). http:// www.guttmacher.org/pubs/tgr/06/5/ gr060504. html (accessed 15 Dec 2004).

10 Foss $\mathrm{AM}$, Watts $\mathrm{CH}$, Vickerman $\mathrm{P}$, et al. Condoms and prevention of HIV. BMJ 2004;329:185-6.

11 Anon. Success and challenges in securing reproductive health and rights in Peru. Women's Health Journal, 2003. http://www.reddesalud. org/english/datos/ftp/change2_eng.pdf (accessed 15 Dec 2004)

12 Sylva D. Abstinence success in Uganda resisted by AIDS community. Insight 2003. (quoted in article). http://www.insightmag.com/ global_user_elements/ printpage. $\overline{c f m}$ ? storyid $=342423$ (accessed 15 Dec 2004).

13 Nelson Mandela Foundation Human Sciences Research Council. Nelson Mandela/HSRC study of HIV/AIDS South African national HIV prevalence, behavioural risks and mass media household survey. Cape Town, SA: HSRC, 2002.

14 Hearst N, Chen S. Condom promotion for AIDS prevention in the developing world: is it working? Stud Fam Plann 2004;35:39-47.
15 Richens J, Imrie J, Copas A. Condoms and seat belts: the parallels and the lessons. Lancet 2000;355:400-3.

16 Paton D. The economics of abortion, family planning and underage conceptions. J Health Econ 2002;21:27-41.

17 Paton D. Random behaviour or rational choice? Family planning, teenage pregnancy and STls. Sex Education, (in press).

18 Stephenson JM, Imrie J, Sutton SR. Rigorous trials of sexual behaviour interventions in STD/HIV prevention: what can we learn from them? AIDS 2000;14(suppl 3):S115-24.

19 Cates W. The condom forgiveness factor: the positive spin. Sex Trans Dis 2002;29:350-2.

20 Adler MW. Sexual health - health of the nation Sex Tran Infect 2003;79:85-7.

21 Museveni Y. AIDS is a socioeconomic disease. In: Kanyogonya $\mathrm{E}$, ed. What is Africa's problem? Minneapolis: University of Minnesota Press, 2000:247-55

22 Hearst N, Hulley SB. Preventing the heterosexual spread of AIDS; are we giving our patients the best advice? JAMA 1988;259:2428-32.

23 Hudson CP. Concurrent partnerships could cause AIDS epidemics. Int J STD AIDS 1993;4:249-53.

24 Wilson D. Partner reduction and the prevention of HIV/AIDS. BMJ 2004;328:848-9.

25 Shelton JD, Halperin DT, Nantulya V, et al. Partner reduction is crucial for balanced " $A B C$ " approach to HIV prevention. BMJ 2004;328:891-3.

26 Genuis SJ, Genuis SK, Adolescent behaviour should be a priority. BMJ 2004;328:894

27 Kmietowicz Z. Women are being let down in efforts to stem HIV/AIDS. BMJ 2004;328:305

28 Rankin W, Wilson C. African women with HIV: faith-based answers might ease the social problems that lead to AIDS. BMJ 2000;321:1543-4.

29 Ingham R, Stammers T. Should doctors advise adolescents to abstain from sex? BMJ 2000;321:1520-2.

30 Singh S, Darroch JE, Bankole A. A, B and C in Uganda; roles of abstinence, monogamy and condom use in HIV decline. http:// www.guttmacher.org/pubs/or_abc03.pdf (accessed 14 Dec 2004).

31 Bellis M, Hughes K, Ashton JR. The promiscuous 10\%. J Epidemiol Community Health 2004;58:889-90.

32 Brückner H, Bearman P. After the promise: the STD consequences of adolescent virginity pledges. J Adolesc Health 2005;36:271-8.

33 Columbia University. http:// www.sociology.columbia.edu/people/faculty/ bearman/papers/std_prevention.pdf.

34 Anon. Birth rate among young US teenagers is lowest in years. BMJ 2004;329:1254.

35 Mohn JK, Tingle LR, Finger R. An analysis of the causes of the decline in non-marital birth and pregnancy rates for teens from 1991-1995. Adolesc Fam Health 2003;3:39-47.

36 Santelli JS, et al. Can changes in sexual behaviours among high school students explain the decline in teenage pregnancy rates in the 1990s? J Adolesc Health 2004;35:80-90.

37 Halperin DT, Steiner MJ, Cassell MM, et al. The time has come for common ground on preventing sexual transmission of HIV. Lancet 2004:364:1913-15.

38 Abraham P. Hooked on failure. (quote in article). World Magazine 2004;Nov 6. http:// www.worlamag.com. 